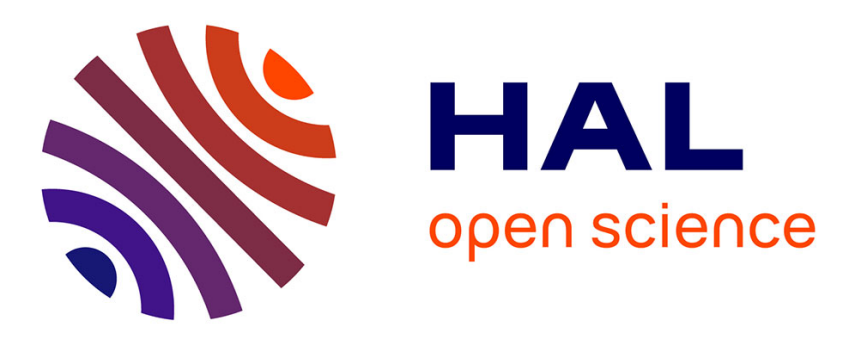

\title{
Towards redox-switchable organocatalysts based on bidentate halogen bond donors
}

\author{
E. Engelage, H. Hijazi, M. Gartmann, L.-M. Chamoreau, B. Schöllhorn, S.
} Huber, Claire Fave

\section{- To cite this version:}

E. Engelage, H. Hijazi, M. Gartmann, L.-M. Chamoreau, B. Schöllhorn, et al.. Towards redoxswitchable organocatalysts based on bidentate halogen bond donors. Physical Chemistry Chemical Physics, 2021, 23 (7), pp.4344-4352. 10.1039/d0cp06612e . hal-03162860

\section{HAL Id: hal-03162860 \\ https://hal.science/hal-03162860}

Submitted on 8 Mar 2021

HAL is a multi-disciplinary open access archive for the deposit and dissemination of scientific research documents, whether they are published or not. The documents may come from teaching and research institutions in France or abroad, or from public or private research centers.
L'archive ouverte pluridisciplinaire HAL, est destinée au dépôt et à la diffusion de documents scientifiques de niveau recherche, publiés ou non, émanant des établissements d'enseignement et de recherche français ou étrangers, des laboratoires publics ou privés. 


\title{
Towards redox-switchable organocatalysts based on bidentate halogen bond donors $\dagger$
}

\author{
E. Engelage, (i) $\star^{a}$ H. Hijazi, (D) $\star^{b}$ M. Gartmann, ${ }^{a}$ L. $-M$. Chamoreau, ${ }^{c}$ B. Schöllhorn, ${ }^{*}$ \\ S. M. Huber (D) $*^{a}$ and C. Fave (iD $*^{b}$
}

Redox-active bidentate halogen bond donors based on halopyridinium groups as halogen-bond donating units were synthesized and their structures were elucidated by X-ray diffraction analyses and DFT calculations. Via reversible twofold reduction, these dicationic species can be transformed to neutral compounds which should be much weaker Lewis acids. The corresponding electrochemical data were obtained, and CV as well as UV-vis and NMR techniques were also used to determine binding constants of these halogen bond donors to halides. While all titrations agree on the relative order of binding strengths (with chloride being bound strongest), there are marked deviations in the overall affinity constants which are discussed. In contrast to earlier azo-bridge analogues, the ethylene-linked variants presented herein do not oxidize halides, and thus the novel halogen bond donors could also be used as Lewis acidic organocatalysts in a halide abstraction benchmark reaction, yielding a performance similar to bis(haloimidazolium)-derived catalysts.

\section{Introduction}

Recently we have demonstrated the possibility to tune and control the strength of halogen bonding (XB) by electrochemically switching the redox state of the respective electroactive $\mathrm{XB}$ donors or acceptors. The observed shift of the standard potentials can be attributed to a stabilization of the oxidized or reduced redox probes via charge-assisted halogen bonding. The first proof of concept was brought for $p$-quinones playing the role of electrochemically active XB-acceptors. ${ }^{1}$ Since then it has been applied to various types of redox active XB-donors such as iodinated TTF, ${ }^{2}$ ferrocene ${ }^{3}$ or viologen ${ }^{4}$ derivatives confirming the interesting potential of electrochemical techniques as a powerful tool to detect and control XB in solution. ${ }^{5}$ In parallel we described the use of halogenated azo-bis-pyridinium derivatives as activators in a proof-of-principle reaction (Scheme 1, $\mathbf{X}_{4}$-2 derivatives). ${ }^{6}$ Even though the activity of these halogen bond donors was very promising, the analysis of the reaction was severely complicated by a side reaction, in which the bromide liberated from the $\mathrm{S}_{\mathrm{N}} 1$ substrate was oxidized by the

\footnotetext{
${ }^{a}$ Fakultät für Chemie und Biochemie, Ruhr-Universität Bochum, Universitätsstrasse 150, 44801 Bochum, Germany. E-mail: stefan.m.huber@rub.de

${ }^{b}$ Université de Paris - Laboratoire d'Electrochimie Moléculaire, CNRS, F-75006

Paris, France. E-mail: claire.fave@u-paris.fr, bernd.schollhom@u-paris.fr

${ }^{c}$ Institut Parisien de Chimie Moléculaire, IPCM, CNRS - Sorbonne Université,

4 place Jussieu, 75252 Paris, France

$\dagger$ Electronic supplementary information (ESI) available. See DOI: 10.1039/ docp06612e

$\$$ Contributed equally.
}

halogen bond donor to form elemental bromine and the hydrazine form of the donor. Careful comparison experiments could still demonstrate that the azo-bis-pyridinium derivatives $\mathbf{X}_{\mathbf{4}}$-2 (Scheme 1) were active through halogen bonding, but the observed redox activity does of course strongly limit the potential application of these halogen-based Lewis acids in halide abstraction reactions. The situation should be different, however, for the $\mathrm{C}$ analogous tetrachloro, tetrabromo and tetraiodo stilbene derivatives $\mathbf{X}_{\mathbf{4}} \mathbf{- 1}$ (Scheme 1), which should be much less sensitive to reduction. In fact, purposeful reduction of these compounds by electrochemistry would allow to basically switching off their halogen bonding capabilities. Changing the XB-donor strength of such bidentate ligands via a reversible electrochemical reaction can lead to a redoxswitchable receptor. In this work, we report the preparation of the novel receptors $\mathbf{X}_{\mathbf{4}} \mathbf{- 1}$, the investigation of their XB-donor properties depending on the oxidation state and the evaluation of their catalytic properties. Their interesting potential as redox-switchable catalysts ${ }^{7,8}$ in organocatalysis is discussed.

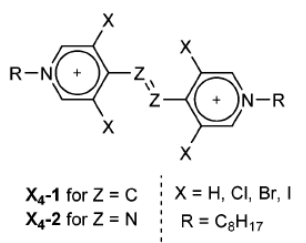

Scheme 1 Stilbene and azo derivatives $\mathrm{X}_{4}-1$ and $\mathrm{X}_{4}-2$ 
In-depth studies on the determination of the thermodynamic binding constants towards anions have been performed using multiple analytical techniques affording valuable quantitative data on XB strength in solution, a domain in which systematic data are still longed for. ${ }^{9}$

\section{Results and discussion}

\section{Synthesis and characterization}

Different synthetic strategies have been undertaken for the preparation of the target compounds $\mathrm{X}_{4}-\mathbf{1}(\mathrm{X}=\mathrm{H}, \mathrm{Cl}, \mathrm{Br}, \mathrm{I})$ (Scheme S1, ESI $\dagger$ ). In order access the target compounds we followed two separate pathways, starting either from 4-picolin (1) or 3,5-dihalopyridines (4a-b). For the non-halogenated species 3 (Scheme 2), 4-picolin (1) was transformed into 4-picolinyl-trimethylsilane (2) by lithiation with LDA at low temperatures and subsequent quenching with TMSCl. In a following Peterson olefination, 2 was lithiated with LDA and treated with isonicotinaldehyde. ${ }^{10}$ After several successive precipitations diaza-stilbene 3 was obtained as the pure $E$-isomer. Alkylation with octyltriflate afforded $\mathrm{H}_{4}-1^{2+}$, following a published procedure. ${ }^{6}$ For the synthesis of the halogenated compounds two distinct procedures were used, depending on the nature of the halogen atom (Scheme 3). Formylation of the 3,5-dichloro and 3,5 dibromo pyridines $\mathbf{4 a - 4 b}$ afforded the respective aldehydes $5 \mathbf{a}-\mathbf{5} \mathbf{b} .{ }^{11}$ The analogue 3,5-diiodoisonicotinaldehyde $(5 \mathrm{c})$ could not be obtained ${ }^{12}$ with this procedure, probably due to the buttressing effect of the flanking iodines. ${ }^{13}$ After methylation of $4 \mathbf{b}$ with $\mathrm{CH}_{3} \mathrm{I}$ and halide exchange on the resulting 3,5 dibromo-4-picolin (6), the diiodinated derivative 7 was obtained. Refluxing of 7 in DMF-DMA ${ }^{14}$ afforded enamine 8 which could be oxidized with sodium periodate ${ }^{15}$ to the key intermediate $5 \mathbf{c}$.

The aldehydes 5 a-c were reduced with $\mathrm{NaBH}_{4}$ affording the corresponding carbinols $\mathbf{9 a - c}$ (Scheme 4). Conversion to the picolinyl bromides 10a-c was conducted with thionyl bromide in methylene chloride. An Arbuzov reaction of picolinyl bromides with triethylphosphite in a sealed vessel at $110{ }^{\circ} \mathrm{C}$ yielded quantitatively the corresponding diethyl phosphonates $11 \mathrm{a}-\mathrm{c}$. After lithiation with LDA and subsequent addition of the respective aldehydes $\mathbf{5 a - c}$, the corresponding azastilbenes 12a-c were isolated after filtration and trituration. Alkylation with $n$-octyltriflate afforded the vinylogous bipyridinium derivatives $\mathrm{Cl}_{4}-\mathbf{1}^{2+}, \mathrm{Br}_{4}-\mathbf{1}^{2+}$ and $\mathrm{I}_{4}-\mathbf{1}^{2+}$.

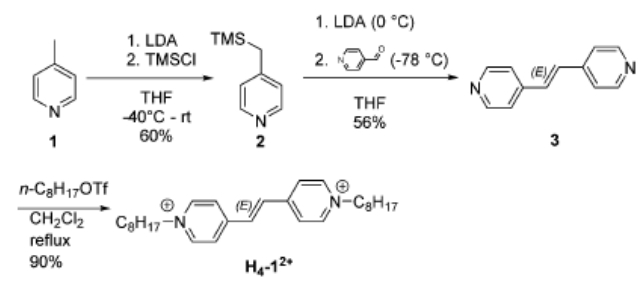

Scheme 2 Synthesis of the non-halogenated derivative $\mathrm{H}_{4}-\mathbf{1}^{2+}$
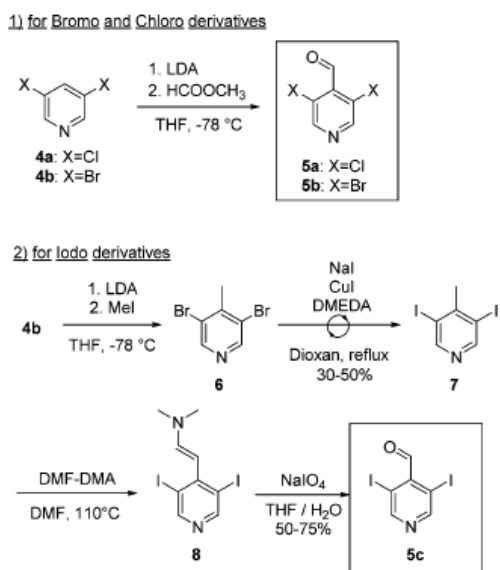

Scheme 3 Synthesis of the 3,5-dihalogeno-isonicotinaldehyde $5 \mathrm{a}, \mathbf{5 b}$ and $5 c$

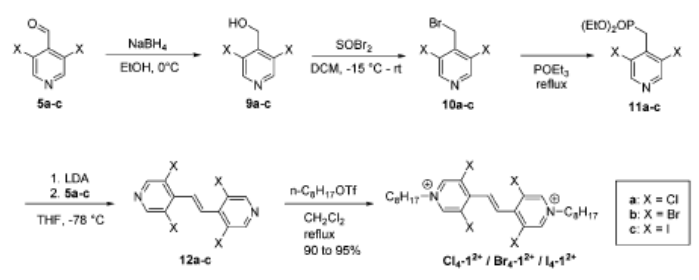

Scheme 4 Synthesis of the targeted molecules $\mathrm{Cl}_{4}-1^{2+}, \mathrm{Br}_{4}-\mathbf{1}^{2+}$ and $\mathrm{I}_{4}-\mathrm{1}^{2+}$

The electrochemical behaviour of the three extended viologens $\mathrm{H}_{4}-\mathbf{1}^{2+}, \mathrm{Br}_{4}-\mathbf{1}^{2+}$ and $\mathrm{I}_{4} \mathbf{- 1}^{2+}$ was investigated by cyclic voltammetry (CV) in DMF with tetrabutylammonium hexafluorophosphate $\left(n \mathrm{Bu}_{4} \mathrm{PF}_{6}\right)$ as supporting electrolyte. Two different behaviors were observed. The CV of $\mathbf{H}_{4^{-1}} \mathbf{1}^{2+}$ exhibits two reversible single-electron reduction waves (Fig. 1, black trace) with formal standard potentials (vs. SCE) of -0.46 and $-0.66 \mathrm{~V}$ corresponding to the sequential

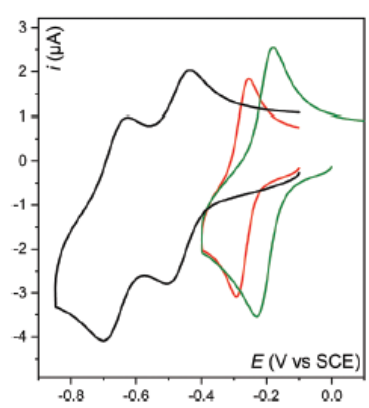

Fig. $1 \mathrm{CVs}$ of $0.1 \mathrm{mM}$ of $\mathrm{I}_{4}-1^{2+}$ (red trace), $\mathrm{Br}_{4}-^{-1^{2+}}$ (green trace) and $\mathrm{H}_{4}$ $1^{2+}$ (black trace) in $0.1 \mathrm{MnBu} \mathrm{PF}_{6} / \mathrm{DMF}$ on a glassy carbon electrode (3 mm-diameter) at $298 \mathrm{~K} . \nu=0.1 \mathrm{~V} \mathrm{~s}^{-1}$. 
formation of the radical cation $\left(\mathrm{H}_{4}-1^{\bullet+}\right)$ and the neutral fully reduced species $\left(\mathrm{H}_{4}-1\right)$, respectively (Table $\mathrm{S} 1$, $\left.\mathrm{ESI}^{\dagger}\right)$. In contrast, CVs recorded for $\mathrm{Br}_{4}-\mathbf{1}^{2+}$ and $\mathrm{I}_{4}-\mathbf{1}^{2+}$, present only one single reversible wave (Fig. 1, green and red traces) corresponding to a two-electron transfer (ET) process respectively at -0.20 and $-0.27 \mathrm{~V}$ vs. SCE (Table S1, ESI $\dagger$ ) leading directly to the neutral species. Owing to the electron withdrawing effect of the halo substituents, the formal standard potentials of the halogenated derivatives are significantly less negative compared to the parent compound $\mathrm{H}_{4} \mathbf{1}^{2+}$. The different mechanism (two single-electron $v$ s. one twoelectron transfer process) can be attributed to steric hindrance.

The presence of four bromo or iodo substituents probably causes a strong conformational torsion leading to a disruption of the $\pi$-conjugated system of the molecules. In the case of $\mathrm{I}_{4}-1^{2+}$, an additional wave was observed at $-1.70 \mathrm{~V}$, corresponding to the signature of a dissociative C-I bond reduction (Fig. S6 red trace, ESI + ). ${ }^{16}$ In all cases, a linear dependence of the peak currents on the square root of the scan rate confirms diffusional electrochemical reactions without any adsorption phenomena of the studied compounds (Fig. S7-S9, ESI + ).

Crystals of $\mathrm{I}_{4} \mathbf{- 1}^{2+}$ triflate salt $\left[\mathrm{I}_{4}-\mathbf{1}^{2+}\right.$. $\left.\left(\mathrm{TfO}^{-}\right)_{2}\right]$ were obtained by slow evaporation of a solution in an ACN/DMSO/benzene solvent mixture, the chloride complex $\left[\mathrm{I}_{4^{-}} \mathbf{1}^{2+} \cdot\left(\mathrm{Cl}^{-}\right)\left(\mathrm{TfO}^{-}\right)\right]$was crystallized from a DMF solution, and the dichloride $\left[\mathbf{I}_{4}-1^{2+}\right.$. $\left.\left(\mathrm{Cl}^{-}\right)_{2}\right]$ by the slow solvolysis of benzhydryl chloride in acetonitrile and evaporation of the solvent over months, since the direct addition of chloride salts only lead to precipitation (Fig. 2 and Fig. S10-S12, ESI $\dagger$ ).

The three compounds crystallized in the triclinic space group $P \overline{1} . I_{4}-1^{2+}$ and its dichloride contain only one bipyridine molecule in the unit cell, displaying an inversion center on the ethylene bridge (Fig. 2 and Table 1). The triflate anion in $\left[\mathbf{I}_{4}-1^{2+}\right.$. $\left.\left(\mathrm{TfO}^{-}\right)_{2}\right]$ is bound by I1 $(2.94 \AA, 84 \% \mathrm{vdW})$ while I2 interacts rather loosely with $\mathrm{O} 1$ and $\mathrm{O} 2$. The distances are about $3.44 \AA$, which is only $1 \%$ shorter than the sum of the vdW radii. The CI2 $\cdots \mathrm{O}$ angles are $147^{\circ}$ and $164.5^{\circ}$, so that the interaction cannot be considered a XB but a mere packing effect. In contrast, the crystal structure of the complex $\left[\mathbf{I}_{4}-1^{2+} \cdot\left(\mathrm{Cl}^{-}\right)\left(\mathrm{TfO}^{-}\right)\right]$displays four non covalent $\mathrm{I} \cdots \mathrm{Cl}$ contacts $\left(d_{\mathrm{I}} \cdots \mathrm{Cl}=3.09-3.31 \AA\right)$ of $11 \%$
Table 1 Halogen bond geometry in the crystal structures of compounds $\mathrm{I}_{4}-1^{2+}$ and $\left[\mathrm{I}_{4}-\mathbf{1}^{2+}, \mathrm{Cl}^{-}\right]$: inter atomic distances $(d)$ and angles $(\angle)$

\begin{tabular}{|c|c|c|c|c|}
\hline$\left[\mathbf{I}_{4^{-}} \mathbf{1}^{2+} \cdot\left(\mathrm{TfO}^{-}\right)_{2}\right]^{a}$ & $d_{\mathrm{I} \ldots \mathrm{O}^{a}}$ & $\%$ vdW & $\angle \mathrm{X}-\mathrm{I} \cdots \mathrm{O}^{b}$ & $d_{\mathrm{C} \cdots 1}^{a}$ \\
\hline $\mathrm{C} 2-\mathrm{I} 1 \cdots \mathrm{O} 1$ & 2.94 & 84.0 & 173.5 & 2.09 \\
\hline $\mathrm{C} 4-\mathrm{I} 2 \cdots \mathrm{O} 1$ & 3.45 & 98.6 & 147.0 & 2.09 \\
\hline $\mathrm{C} 4-\mathrm{I} 2 \cdots \mathrm{O} 2$ & 3.43 & 98.0 & 164.5 & 2.09 \\
\hline$\underline{\left[\mathbf{I}_{4}-1^{2+} \cdot\left(\mathrm{Cl}^{-}\right)\left(\mathrm{TfO}^{-}\right)\right]}$ & $d_{1 \cdots \mathrm{Cl}^{a}}$ & $\%$ vdW & $\angle \mathrm{X}-\mathrm{I} \cdots \mathrm{Cl}^{b}$ & $d_{\mathrm{C} \cdots \mathrm{I}^{a}}$ \\
\hline C3-I1 $\cdots$ Cl1 & 3.08 & 82.6 & 174.7 & 2.10 \\
\hline 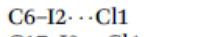 & 3.31 & 88.7 & 159.6 & 2.10 \\
\hline 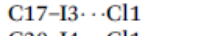 & 3.13 & 83.9 & 167.7 & 2.10 \\
\hline C20-I $\cdots$ Cl1 & 3.24 & 86.9 & 168.3 & 2.11 \\
\hline$\underline{\left[\mathrm{I}_{4}-1^{2+} \cdot\left(\mathrm{Cl}^{-}\right)_{2}\right]}$ & $d_{\mathrm{I} \cdots \mathrm{Cl}}{ }^{a}$ & $\% \mathrm{vdW}$ & $\angle \mathrm{X}-\mathrm{I} \cdots \mathrm{Cl}^{b}$ & $d_{\mathrm{C} \cdots \mathrm{I}}{ }^{a}$ \\
\hline $\begin{array}{l}\text { C2-I1 } \cdots \text { Cl } 1 \\
\text { C4-I2 } \cdots \text { Cl1 }\end{array}$ & $\begin{array}{l}3.15 \\
3.31\end{array}$ & $\begin{array}{l}85.6 \\
89.9\end{array}$ & $\begin{array}{l}172.8 \\
160.9\end{array}$ & $\begin{array}{l}2.10 \\
2.11\end{array}$ \\
\hline$a_{1}-12 \cdots{ }^{b}$ & & & & \\
\hline
\end{tabular}

to $17 \%$ shorter than the sum of the theoretical vdW radii $(3.74 \AA)^{17}$ (Fig. 2 and Table 1). This fact and the large angles $\left(\angle \mathrm{C}-\mathrm{I} \cdots \mathrm{Cl}=159.6^{\circ}-174.7^{\circ}\right)$ clearly suggest directional halogen bonding. The tetra coordination of $\mathrm{Cl}^{-}$certainly results in an overall strong XB complex thus displacing the probably weakly bonded triflates.

The asymmetric unit contains two different moieties of $\mathrm{I}_{4}-\mathbf{1}^{2+}$, a chloride anion, and a disordered triflate with short contacts to the aromatic pyridine protons. Infinite chains alternating between XB donors $\mathrm{I}_{4}-1^{2+}$ and acceptors $\mathrm{Cl}^{-}$are formed. The $1: 1$ stoichiometry for $\mathrm{I}_{4}^{-1} \mathbf{1}^{2+}$ and $\mathrm{Cl}^{-}$confirms the key role of halogen bonding in this self-assembled structure. Triflate is here the second anion counterbalancing the overall charge of the dications. The pyridinium rings within each molecule are almost coplanar whereas the linking $\mathrm{C}=\mathrm{C}$ double bond is strongly tilted of about $50^{\circ}$ to $60^{\circ}$. In the structure of $\left[\mathrm{I}_{4} \mathbf{- 1}^{2+} \cdot\left(\mathrm{Cl}^{-}\right)_{2}\right]$ the overall neutral dichloride complex appears to be assembled via weak $\mathrm{CH} \cdots \mathrm{Cl}^{-}$hydrogen bonds. Details of the data collection and refinement are given in the $\mathrm{ESI}^{\dagger}$ (Tables S2-S10).

The strongly tilted conformation of the dications (tilt angles of about $50^{\circ}$ to $60^{\circ}$ ) in the solid state is in agreement with the
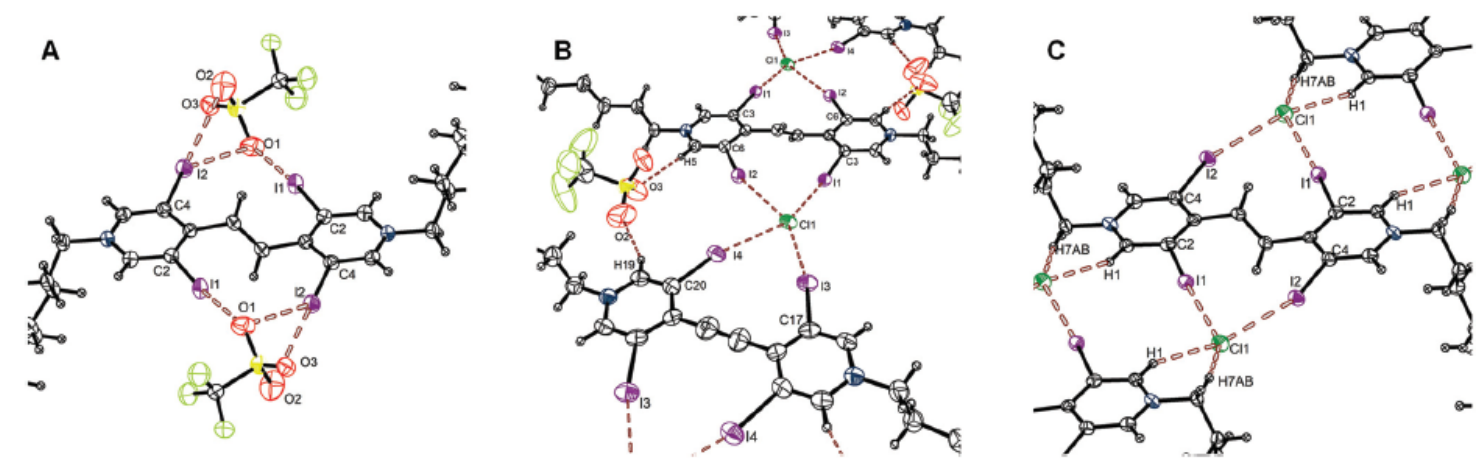

Fig. 2 Crystal structures of $\left[\mathrm{I}_{4} \mathbf{1}^{2+} \cdot\left(\mathrm{TfO}^{-}\right)_{2}\right](\mathrm{A}),\left[\mathrm{I}_{4}-1^{2+} \cdot\left(\mathrm{Cl}^{-}\right)\left(\mathrm{TfO}^{-}\right)\right](\mathrm{B})$, and $\left[\mathrm{I}_{4} \mathbf{- 1}^{2+} \cdot\left(\mathrm{Cl}^{-}\right)_{2}\right](\mathrm{C})$. Ellipsoids are depicted at their $50 \%$ probability level. C black, $\mathrm{N}$ - blue, $\mathrm{O}$ - red, $\mathrm{F}$ - light green, $\mathrm{S}$ - yellow, $\mathrm{Cl}$ - dark green, I - purple. 
observation of a two electron transfer process during the electrochemical reduction of the dication. Even in homogeneous solution the steric hindrance of the relatively big halide substituents and the rigid $\mathrm{H}-\mathrm{C}=\mathrm{C}-\mathrm{H}$ unit most probably lead to a conformation in which the heteroaromatic systems are not electronically coupled via the $\pi$-conjugated system and this even in the XB complex.

Additionally, the formation of the infinite alternating donor acceptor chains explains the solubility issues observed in ACN and DMSO. The relatively less polar ACN is incapable of separating the charges and upon chloride addition the polymeric complex precipitates. DMSO on the other hand is apparently able to form competitive $\mathrm{XB}$ to the viologens, thus occupying the second binding site, until getting replaced by the first chloride anion, after exceeding 1 eq.

\section{DFT calculations}

In order to obtain further information on the structures of $\mathbf{I}_{4^{-}}-1^{2+}$ and $\mathrm{H}_{4}-\mathbf{1}^{2+}$ (as well as their onefold or twofold reduced analogues), DFT calculations (M06-2X D3 def2-TZVP, for further details and coordinates see the ESI $\dagger$ ) were performed on model compounds in which all octyl groups were replaced by methyl $\left(\mathrm{I}_{4}-\mathbf{1}^{\prime 2+}\right.$ and $\mathrm{H}_{4} \mathbf{1}^{12+}$ ). Our main goal was to compare the geometries of these compounds and to check whether bidentate halogen bonding with halides was geometrically feasible for $\mathbf{I}_{4}-1^{\prime 2+}$, and thus the interpretation will focus entirely on those aspects (as we are well aware that the exact calculation of redox potentials and halogen bonding energies can be tricky). To further verify the performance of the applied theoretical model, we compared the bond lengths in $\mathbf{I}_{4} \mathbf{- 1}^{\prime 2+}$ with the ones of the cation in the crystal structure of $\left[\mathbf{I}_{4}-\mathbf{1}^{2+} \cdot\left(\mathrm{TfO}^{-}\right)_{2}\right]$, and deviations were (often far) below $0.01 \AA$. The optimized gas phase structures obtained for all six compounds $\left(\mathrm{H}_{4} \mathbf{1}^{\prime 2+}, \mathbf{H}_{4^{-1}} \mathbf{1}^{\prime+}, \mathbf{H}_{4^{-}} \mathbf{1}^{\prime}\right.$ as well as $\mathbf{I}_{4}-^{12+}, \mathbf{I}_{4}-1^{\prime+}, \mathbf{I}_{4} \mathbf{1}^{\prime}$ ) clearly indicated that all bond lengths of the core structures were very similar (with deviations $<0.1 \AA$ A ) between two comparable species (e.g. $\mathbf{I}_{4}-^{12+}$ and $\mathrm{H}_{4}-1^{\prime 2+}$, Fig. 3). However, there is a clear difference concerning the planarity when comparing the iodinated and the noniodinated compounds. Due to the size of the four iodine substituents, all iodinated compounds deviate more or less strongly from planarity, while all non-iodinated compounds are more or less planar (with only $\mathbf{H}_{4}-\mathbf{1}^{\prime 2+}$ featuring a slight tilt between the two planes of pyridines, tilt angle approx. $29^{\circ}$ as measured by the I-C $\cdots \mathrm{C}-\mathrm{I}$ dihedral angle; see $\left.\mathrm{ESI}^{\dagger}\right)$. In the iodinated compounds, $\mathbf{I}_{4}-1^{\prime 2+}$ shows the strongest deviation from planarity (tilt angle $72^{\circ}$ ), and similar to the progression

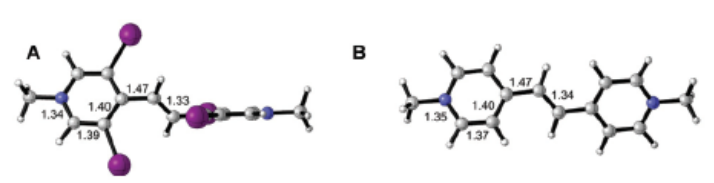

Fig. 3 Optimized gas phase structures of $\mathrm{I}_{4}-\mathbf{1}^{\prime 2+}(\mathrm{A})$ and $\mathrm{H}_{4}-\mathbf{1}^{2+}$ (B), with octyl groups replaced by methyl. Bond lengths in $\hat{A}$. Graphics by CYLview. ${ }^{18}$

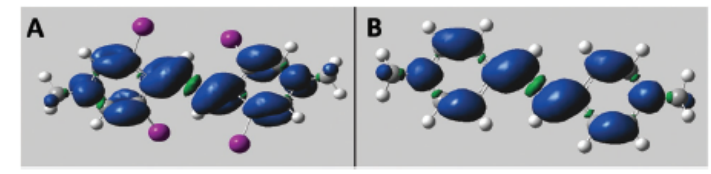

Fig. 4 Spin densities of $\mathrm{I}_{\mathbf{4}}-\mathbf{1}^{\prime+}(\mathrm{A})$ and $\mathrm{H}_{4}-\mathbf{1}^{\prime+}(\mathrm{B})$.

in the series $\mathbf{H}_{4}-\mathbf{1}^{\prime \boldsymbol{n}^{+}}$( $n=2$ to 0 ), the structures of $\mathbf{I}_{4} \mathbf{1}^{\prime+}$ (tilt angle $43^{\circ}$ ) and $I_{4}-1^{\prime}$ (tilt angle $17^{\circ}$ ) become more planar. In the latter case, this approach to planarity is accompanied by slight distortions of the carbon-iodine bonds, likely due to steric repulsion between the iodines (see ESI $\dagger$ ). The spin densities of the radical intermediates $\mathbf{I}_{4} \mathbf{- 1}^{\prime+}$ and $\mathbf{H}_{4} \mathbf{1}^{\prime \prime+}$ are depicted in Fig. 4. A coarse comparison of the two images indicates that the spin is similarly distributed in both compounds despite the differences in tilt angles $\left(43^{\circ}\right.$ vs. $\left.0^{\circ}\right)$ mentioned above. The latter do not seem to have a strong influence on delocalization.

In the optimized structure of $\mathbf{I}_{4}-^{\prime 2+}$ (Fig. 3 left), the electrophilic carbon-iodine axes on different pyridine moieties are almost perpendicular to each other, and thus a bidentate coordination of Lewis acids like halides seems improbable at first glance. In order to investigate the binding behavior further, the chloride, bromide and iodide complex of $\mathrm{I}_{4}-^{12+}$ were optimized by the same means as mentioned above. All complexes feature a clear bidentate coordination of the halide, as is illustrated for chloride in Fig. 5 , in which the two pyridine moieties of the halogen bond donor become almost co-planar.

There is, however, a slight distortion of the halogen bond donors, as the iodines which are coordinated to the halide are closer to each other than the ones on the opposite side of the molecule ( $3.58 \AA$ A vs. $4.06 \AA$ for the chloride complex, Fig. 5). In all complexes, two slightly different halogen bonds are observed, with the stronger one always also being the slightly more linear one (see ESI $\dagger$ ). Even though the determination of adduct energies was not our primary goal, a comparison of the iodine-halide distances seems to reveal a trend: compared to the respective sum of the van der Waals radii, the distance is shortest for the chloride complex $(75 \%$ and $79 \%$ of van der Waals radii) and the longest for iodide (79\% and $82 \%)$, with bromide in-between $(77 \%$ and $80 \%)$. Thus, these gas-phase calculations seem to predict that chloride is most strongly bound by the halogen bond donors.

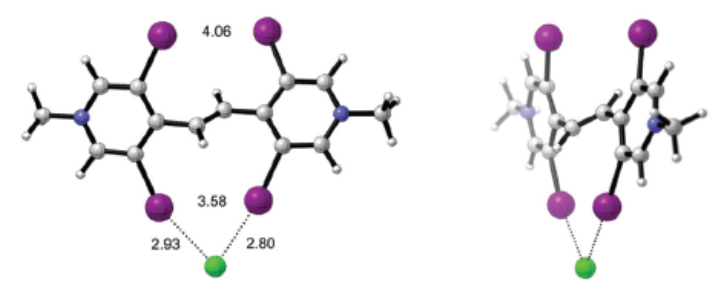

Fig. 5 Optimized gas phase structure of the complex of $\mathrm{I}_{4}-\mathbf{1}^{\prime 2+}$ with chloride (front and side view). Distances for $\mathrm{I}-\mathrm{Cl}$ and $\mathrm{I}-\mathrm{I}$ in $\mathrm{A}$. 

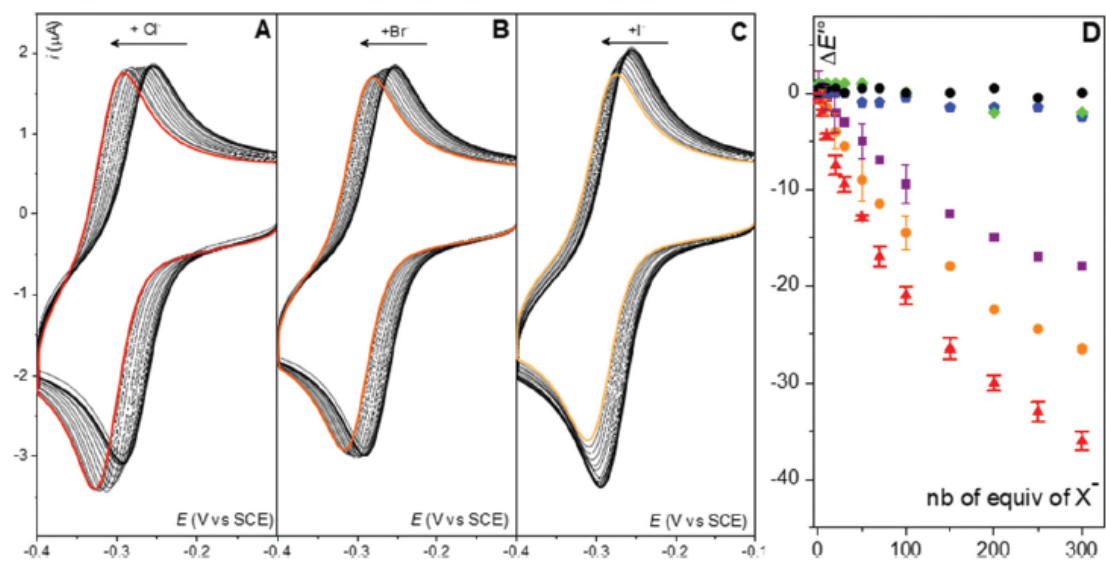

Fig. $6 \mathrm{CVs}$ of $0.1 \mathrm{mM} \mathrm{L}_{4}-1^{2+}$ in $0.1 \mathrm{MnBu}_{4} \mathrm{PF}_{6} / \mathrm{DMF}$ in the absence and in the presence of increasing concentrations (from 0 to $\left.30 \mathrm{mM}\right)$ of $n \mathrm{Bu}_{4} \mathrm{X}:(\mathrm{A}) \mathrm{X}=$ $\mathrm{Cl}^{-}$, (B) $\mathrm{X}=\mathrm{Br}^{-}$and $(\mathrm{C}) \mathrm{X}=\mathrm{I}^{-} . T=298 \mathrm{~K}, \nu=0.1 \mathrm{~V} \mathrm{~s}^{-1}$. (D) Variation of the formal reduction potential of $\mathrm{I}_{4}-1^{2+}$ as function of $\mathrm{LB}^{2}$ added $\left(\mathrm{Cl}^{-}\right.$: red, $\mathrm{Br}^{-}$. orange, $\mathrm{I}^{-}$: violet, $\mathrm{NO}_{3}^{-}$: blue, $\mathrm{HSO}_{4}^{-}$: green and $\mathrm{OTf}^{-}$: black). The error bars indicated for chloride, bromide and iodide are standard deviations and each point is the average of at least three experiments.

\section{3. $\mathrm{XB}$ detection}

3.1 Cyclic voltammetry. The electrochemical behaviour of the three derivatives $\mathbf{I}_{4}-\mathbf{1}^{2+}, \mathrm{Br}_{4}-\mathbf{1}^{2+}$ and $\mathrm{H}_{4}-\mathbf{1}^{2+}$ was studied by $\mathrm{CV}$ in the presence of various anions. The DMF solutions contained $0.1 \mathrm{M} \mathrm{nBu}{ }_{4} \mathrm{PF}_{6}$ and in the titration experiments, the total salt concentration was kept constant never exceeding $0.11 \mathrm{M}$. In presence of 100 equivalents of chloride $\left(n \mathrm{Bu}_{4} \mathrm{Cl}\right)$ the formal standard potential of the reduction wave of $\mathrm{I}_{4}-\mathbf{1}^{2+}$ was shifted toward more negative potentials $\left(\Delta E^{\circ \prime}=-21 \mathrm{mV}\right)$ (Fig. 6A).

Smaller but still significant potential shifts were recorded when adding bromide $\left(-15 \mathrm{mV}\right.$ for 100 eq. $\left.\mathrm{Br}^{-}\right)$or iodide (-10 $\mathrm{mV}$ for 100 eq. I) (Fig. 6B and $\mathrm{C}$ and Table 2). These observations are consistent with a stabilization of the dicationic $\mathbf{I}_{4}-\mathbf{1}^{2+}$ species via charge-assisted non-covalent $\mathrm{XB}$ interactions leading to the complex $\left[\mathbf{I}_{4}-\mathbf{1}^{2+}, \mathrm{Cl}^{-}\right]$. Such a reductive $\mathrm{XB}$ deactivation has been already demonstrated for iodo-phenylviologen derivatives in one of our previous articles. ${ }^{4,5}$ Reduction to the neutral state $\left(\mathbf{I}_{\mathbf{4}}-\mathbf{1}\right)$ proved to significantly decrease the XB-donor strength.

The shift intensity regarding the chosen halide can thus be directly correlated with the charge density of the XB-acceptors $\left(\mathrm{Cl}^{-}>\mathrm{Br}^{-}>\mathrm{I}^{-}\right)$. The less basic oxo-anions OTf, $\mathrm{HSO}_{4}{ }^{-}$or $\mathrm{NO}_{3}{ }^{-}$have been also tested with $\mathbf{I}_{4}-^{-1^{2+}}$ but no significant perturbations of the CVs could be detected (Fig. S20, ESI $\dagger$ ) suggesting a strong selectivity for halide anions. Replacing the iodo-substituents with bromine $\left(\mathrm{Br}_{4}-\mathbf{1}^{2+}\right)$ or hydrogen $\left(\mathrm{H}_{4}-\mathbf{1}^{2+}\right)$ resulted in receptors with no detectable halide affinity (Fig. S21 and $\mathrm{S} 22, \mathrm{ESI} \dagger$ ). These results indicate that under the experimental conditions $\left[\mathrm{C}-\mathrm{Br} \cdot \cdot \mathrm{Cl}^{-}\right] \mathrm{XB}$ interactions are too weak because of the lower polarizability of the XB-donor atom, decreasing for the homologous elements $\mathrm{I}>\mathrm{Br}>\mathrm{Cl}$. Apparently $\mathrm{HB}\left[\mathrm{C}-\mathrm{H} \cdot{ }^{*} \mathrm{Cl}^{-}\right]$is also not competitive with the other noncovalent interactions in the polar liquid electrolyte.
The dependence of the observed formal potential shift $\Delta E^{\circ \prime}$ of $\mathrm{I}_{4}-1^{2+}$ on the anion concentration is represented in Fig. 6D. The titration curves have been fitted according to eqn (1) based on a conventional square scheme mechanism (Scheme 5) assuming a $1: 1$ stoichiometry of the XB complexes according to the observed solid state crystal structure.

$$
\Delta E^{\prime}=E_{2}^{\circ \prime}-E_{1}^{\circ \prime}=-\frac{R T}{n F} \ln \frac{\left(1+K_{\mathrm{ox}}[\mathrm{LB}]\right)}{\left(1+K_{\mathrm{red}}[\mathrm{LB}]\right)}
$$

With $E_{1}^{\circ \prime}$ being the formal standard potential of the redox couple $\mathbf{I}_{4}-\mathbf{1}^{2+} / \mathbf{I}_{4}-1$ and $E_{2}^{\circ \prime}$ the nominal potential depending on the Lewis Base concentration [LB] and $K_{\text {ox }}$ and $K_{\text {red }}$ the thermodynamic affinity constants for the interaction with $\mathbf{I}_{4} \mathbf{- 1}^{2+}$ and $\mathbf{I}_{4^{-}}$ 1 , respectively.

Table 2 Table of standard potential shifts $\left(\Delta E^{\circ \prime}\right)$ for the redox couples dication/cation radical of $\mathrm{I}_{4}-1^{2+}, \mathrm{Br}_{4}-1^{2+}$ and $\mathrm{H}_{4}-1^{2+}$ upon addition of of $n \mathrm{Bu}_{4} \mathrm{X}\left(\mathrm{X}=\mathrm{Cl}, \mathrm{Br}, \mathrm{I}, \mathrm{OTf}, \mathrm{HSO}_{4}\right.$ and $\left.\mathrm{NO}_{3}\right)$ and the corresponding affinity constants $K_{\text {ox }}$ and $K_{\text {red }}$

\begin{tabular}{lllllll}
\hline $\mathrm{X}_{4^{-1}}{ }^{2+}$ & Anion & $\Delta E^{0, a}$ & $\Delta E^{\circ, b}$ & $K_{\mathrm{ox}}{ }^{c}$ & $K_{\mathrm{red}}{ }^{c}$ & $K_{\mathrm{oxx}} / K_{\mathrm{red}}$ \\
\hline $\mathrm{I}_{4^{-1}} \mathbf{1}^{2+}$ & $\mathrm{Cl}^{-}$ & -8 & -21 & 255 & 60 & 4.2 \\
& $\mathrm{Br}^{-}$ & -4 & -15 & 135 & 35 & 3.8 \\
& $\mathrm{I}^{-}$ & -2 & -10 & 55 & 7 & 7.8 \\
& $\mathrm{OTf}^{-}$ & 0 & 0 & - & - & - \\
& $\mathrm{HSO}_{4}{ }^{-}$ & 0 & 0 & - & - & - \\
& $\mathrm{NO}_{3}{ }^{-}$ & 0 & 0 & - & - & - \\
$\mathrm{Br}_{4}-1^{2+}$ & $\mathrm{Cl}^{-}$ & 0 & -4 & 14 & 6 & 2.3 \\
& $\mathrm{Br}^{-}$ & 0 & -3 & 8 & 3 & 2.7 \\
& $\mathrm{I}^{-}$ & 0 & 0 & - & - & - \\
$\mathrm{H}_{4}-1^{2+}$ & $\mathrm{Cl}^{-}$ & 0 & -5 & - & - & -
\end{tabular}

${ }^{a}$ In $\mathrm{mV}$, upon addition of 20 equiv. of $n \mathrm{Bu}_{4} \mathrm{X}$, standard deviation: $\pm 1 \mathrm{mV}$. ${ }^{b} \mathrm{In} \mathrm{mV}$, upon addition of 100 equiv. of $n \mathrm{Bu}_{4} \mathrm{X}$ standard deviation: $\pm 2 \mathrm{mV} .{ }^{c}$ In $\mathrm{M}^{-1}$. 


$$
\begin{gathered}
\mathrm{I}_{\mathbf{4}}-\mathbf{1}^{2 \oplus}, \mathrm{Cl}^{\ominus} \stackrel{E^{\circ \prime}{ }_{1}}{\rightleftharpoons} \mathrm{I}_{\mathbf{4}}-1 \\
\left.\mid \mathrm{I}_{4}-1^{2 \oplus}, \mathrm{Cl}^{\ominus}\right] \stackrel{E^{\circ \prime}{ }_{2}}{\rightleftharpoons}\left[\mathrm{I}_{4}-1, \mathrm{Cl}^{\ominus}\right]
\end{gathered}
$$

Scheme 5 Square scheme mechanism.

Fitting this square scheme model to the experimental titration plots allowed for the determination of the respective affinity constants depending on the oxidation state of the XBdonor. The highest affinity constant has been calculated for an association between $\mathrm{I}_{4}^{-1} \mathbf{1}^{2+}$ and $\mathrm{Cl}^{-}$with a $K_{\text {ox }}$ of $255 \mathrm{M}^{-1}$ (Tables 2 and 3). As expected, the value of the calculated $K_{\text {red }}$ is quite low, indicating only weak interactions between the neutral $\mathbf{I}_{4^{-1}} \mathbf{w}$ with chloride. The markedly weaker Lewis acidity of $\mathbf{I}_{4}-1$ compared to $\mathbf{I}_{4}-1^{2+}$ is also reflected by the size of their corresponding $\sigma$-holes, with a $V_{\mathrm{S}, \max }$ of $57 \mathrm{~kJ} \mathrm{~mol}^{-1}$ for $\mathbf{I}_{4}-1$ and $584 \mathrm{~kJ} \mathrm{~mol}^{-1}$ for $\mathrm{I}_{4}-1^{2+}$. When DFT computations including the SMD1 $8^{19}$ solvation model for DMF were employed to estimate the binding constants, a similar trend was observed, with $K_{\mathrm{ox}}=$ $62 \mathrm{M}^{-1}$ and $K_{\text {red }}=1.6 \times 10^{-5} \mathrm{M}^{-1}$ (even though the difference between the two complexes was much more pronounced in this case, for currently unknown reasons).

The values of $K_{\mathrm{ox}}$ for bromide $\left(135 \mathrm{M}^{-1}\right)$ or iodide $\left(55 \mathrm{M}^{-1}\right)$ are consistent with the relative Lewis basicity. Low affinity constants could be determined for $\mathrm{Br}_{4}-1^{2+}$ taking into account the small potential shifts. The addition of chloride did not show any effect neither on the first reduction wave of $\mathbf{H}_{4}-1^{2+}$ nor on the second.

3.2 UV-vis spectroscopy. The results obtained with CV were compared with titration experiments employing UV-vis absorption spectroscopy. The spectrum of $\mathbf{I}_{4}-\mathbf{1}^{2+}$ was recorded in pure non-deuterated DMF at $298 \mathrm{~K}$ (Fig. 7A, black trace). Then the electrolyte salt $n \mathrm{Bu}_{4} \mathrm{PF}_{6}(0.1 \mathrm{M})$ was added in order to maintain comparable ionic strength to the electrochemical experiments. The maximum absorption peak centred at $334 \mathrm{~nm}$ was attributed to $\pi-\pi^{*}$ transitions. ${ }^{20}$ As illustrated in Fig. 7A (red trace), upon addition of chloride $\left(n \mathrm{Bu}_{4} \mathrm{Cl}\right)$, a decrease of the molar absorption coefficient for the band at $334 \mathrm{~nm}$, accompanied with a slight bathochromic shift of $5 \mathrm{~nm}$ and the appearance of

Table 3 Association constants $\left(K_{\text {ox }} / M^{-1} \pm 6\right) /$ binding free energies $\left(\Delta G / \mathrm{kJ} \mathrm{mol}^{-1} \pm 1\right)$ of various anions with $\mathrm{I}_{4}-1^{2+}$ determined by various techniques

\begin{tabular}{lllll}
\hline Solvent & Anion & $\mathrm{CV}$ & UV-vis & ${ }^{1} \mathrm{H}$ NMR \\
\hline $0.1 \mathrm{M} \mathrm{TBAPF}_{6}$ in DMF & $\mathrm{Cl}^{-}$ & $255(-16.2)$ & $187(-15.3)$ & $34(-10.3)$ \\
& $\mathrm{Br}^{-}$ & $135(-14.4)$ & - & - \\
& $\mathrm{I}^{-}$ & $55(-11.7)$ & - & - \\
& $\mathrm{TfO}^{-}$ & nd & - & - \\
& & & & \\
DMF & $\mathrm{Cl}^{-}$ & - & $1466(-21.4)$ & $313(-4.6)$ \\
& $\mathrm{Br}^{-}$ & - & $365(-17.3)$ & $59(-12.0)$ \\
& $\mathrm{I}^{-}$ & - & nd & $66(-12.3)$ \\
& $\mathrm{TfO}^{-}$ & - & nd & nd
\end{tabular}

nd: not determined.
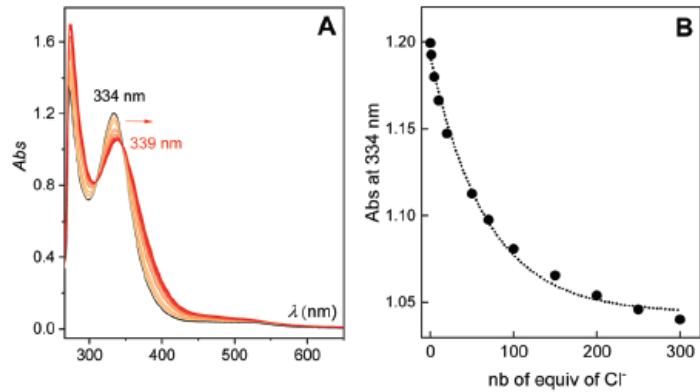

Fig. 7 (A) UV-vis spectra of $0.1 \mathrm{mM} \mathrm{I}_{4}-1^{2+}$, in $0.1 \mathrm{M} \mathrm{nBu}_{4} \mathrm{PF}_{6} / \mathrm{DMF}$ in the presence of increasing equivalents of $\mathrm{Cl}^{-}$(from 0 , black trace up to 300 equivalents, red trace). (B) Variation of the absorbance at $334 \mathrm{~nm}$ as function of added equivalents of chloride. The dash curve was obtained by numerical simulation representing the best fit to the experimental data based on a $1: 1$ stoichiometry using BindFit. ${ }^{21,22}$

an isobestic point. The association constant between $\mathbf{I}_{4}-1^{2+}$ and $\mathrm{Cl}^{-}$in the same solution as used for $\mathrm{CV}$ experiments was determined using BindFit, an online tool for supramolecular chemistry research and analysis. ${ }^{21,22} \mathrm{~A}$ binding constant $K_{\mathrm{a}}$ of $187 \mathrm{M}^{-1}$ was calculated based on a 1:1 stoichiometry (Table 3). It is one order of magnitude smaller than the value obtained in the absence of $n \mathrm{Bu}_{4} \mathrm{PF}_{6}\left(1466 \mathrm{M}^{-1}\right.$, Fig. S23, ESI + ).

This observation highlights the significant competition of electrolyte ions at relatively high concentration $(0.1 \mathrm{mM})$ with the species of interest in the following electrochemical experiments used to quantify halogen bonding.

The association constant of $\mathrm{I}_{4}-\mathbf{1}^{2+}$ with $\mathrm{Br}^{-}$in the absence of $n \mathrm{Bu}_{4} \mathrm{PF}_{6}$ was estimated from the UV-vis data (Fig. S24A, $\mathrm{ESI} \dagger$ ) to be $K_{\mathrm{a}}=365 \mathrm{M}^{-1}$ which is considerably smaller than the value obtained with $\mathrm{Cl}^{-}$under the same conditions. The affinity constant for $\mathrm{I}^{-}$could not be determined (Fig. S24B, ESI + ), probably due to its very weak interaction with $\mathrm{I}_{4} \mathbf{1}^{2+}$.

Titrations with the weak Lewis base, triflate, did not result in any change of the absorption spectrum of $\mathrm{I}_{4^{-}} \mathbf{1}^{2+}$ (Fig. S24D, ESI $\dagger$ ).

Interestingly, the spectrum of the reference compound, the non-halogenated derivative $\mathrm{H}_{4} \mathbf{- 1}^{2+}$, was not at all perturbed by the presence of the Lewis basic chloride at high concentrations (Fig. S25, ESI + ), confirming the XB predominant interaction in the case of $\mathrm{I}_{4^{-1}} \mathbf{1}^{2+}$.

3.3 NMR spectroscopy. Taking advantage of the diamagnetic character of the dicationic receptors, ${ }^{1} \mathrm{H}$ NMR spectroscopy could also be used as a technique in order to determine affinity constants and to confront the results with those of the other techniques described above.

$1 \mathrm{mM}$ solutions of $\mathrm{I}_{4}-\mathbf{1}^{2+}, \mathrm{Br}_{4}-\mathbf{1}^{2+}$ and $\mathrm{H}_{4}-\mathbf{1}^{2+}$ in DMF and for comparison two previously described strong XB-donors, iodolium triflate $13^{23}$ and bisimidazolium $14^{24}$ (Scheme 6) were titrated with increasing amounts of chloride. ${ }^{1} \mathrm{H}$ NMR spectra of the chloride titration of $\mathbf{I}_{4}-1^{2+}$ are shown in Fig. 8 (see also Fig. S26, ESI + ). The signal of the pyridine protons of $\mathbf{I}_{4}-1^{2+}$ is progressively shifting from 8.890 to $9.005 \mathrm{ppm}$ upon the addition of about 83 equivalents of chloride. The corresponding 


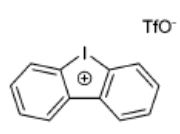

13
14

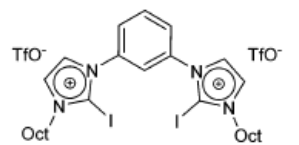

Scheme 6 Structures of the XB-donors iodolium $13^{23}$ and bisimidazolium $14 .^{24}$

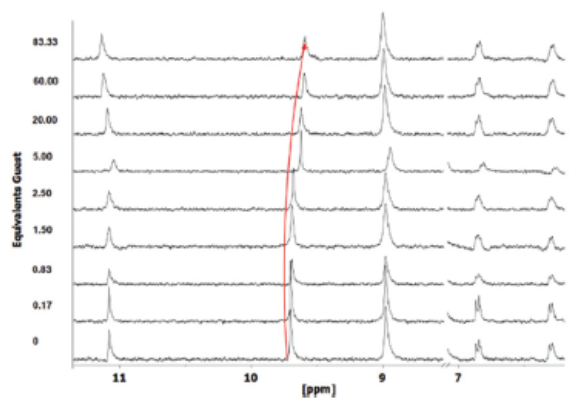

Fig. 8 NMR spectra of the chloride titrations of $\mathrm{I}_{4}-1^{2+}$ under standard suppression conditions. The red trace indicates the shift of the signals of interest. The signals at about $9 \mathrm{ppm}$ and $11.1 \mathrm{ppm}$ are residuals from the DMF. Those appear probably due to interactions with the XB-donors and are absent in pure DMF. The latter one starts shifting at higher ion concentrations.

association constants (1/1 stoichiometry) were determined by using the BindFit program. ${ }^{22}$

With an association constant of $313 \mathrm{M}^{-1}$ (i.e. $\Delta G=14.6 \mathrm{~kJ}$ $\mathrm{mol}^{-1}$ ), $\mathbf{I}_{4} \mathbf{- 1}^{2+}$ exhibits the strongest binding to chloride of the herein studied bidentate derivatives (Fig. 9A). $\mathbf{B r}_{4}-\mathbf{1}^{2+}$ displays a one order of magnitude smaller $K_{\mathrm{a}}$ value of about $28 \mathrm{M}^{-1}$. These results follow the classic trend of the increasing $\mathrm{XB}$ donor strength in the order $\mathrm{Br}<\mathrm{I}^{25}$ For comparison, monodentate iodine(III)-based XB-donor 13 features a binding constant to chloride of $123 \mathrm{M}^{-1}$ under the same conditions. Due to signal overlap, binding affinities could not be determined for
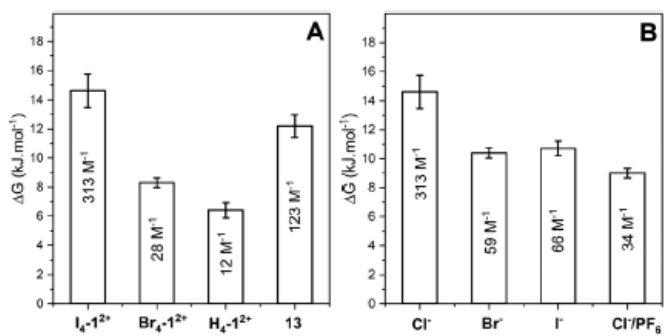

Fig. 9 Binding free energies $\left(\mathrm{kJ} \mathrm{mol}^{-1}\right)$ and affinity constant $\left(\mathrm{M}^{-1}\right)$ deter mined by NMR-titration at $298 \mathrm{~K}$ in DMF-h7 for $(1 \mathrm{mM}) \mathrm{I}_{4}-\mathbf{1}^{2+}, \mathrm{Br}_{4}-\mathbf{1}^{2+}, \mathrm{H}_{4}$ $1^{2+}, 13$ towards chloride (left), and for $\mathrm{I}_{4}-1^{2+}$ towards chloride, bromide iodide and towards chloride in the presence of $0.1 \mathrm{M} \mathrm{nBu}_{4} \mathrm{PF}_{6}$ (right). All compounds were fitted presuming a 1:1 stoichiometry. Association constants were calculated using the BindFit program. ${ }^{24-27}$ bidentate XB donor 14 in this solvent. As expected the affinity constants for the interaction of $\mathbf{I}_{4}-\mathbf{1}^{2+}$ with bromide $\left(59 \mathrm{M}^{-1}\right)$ and iodide $\left(66 \mathrm{M}^{-1}\right)$ are significantly smaller as with chloride $\left(313 \mathrm{M}^{-1}\right)$. The impact of the ionic strength of the solution was also controlled by comparing the recorded spectra during the titration with or without the supporting electrolyte $n \mathrm{Bu}_{4} \mathrm{PF}_{6}$.

As expected and in accordance with electrochemical and UV-vis results, addition of supporting electrolyte induced a decrease of $K_{\mathrm{a}}$ by one order of magnitude $\left(313 \mathrm{M}^{-1}\right.$ and $34 \mathrm{M}^{-1}$, respectively).

These results indicate the significant role of Coulombic interactions.

3.4 Discussion of the determined affinity constants. The three different techniques, CV, NMR and UV-vis spectroscopy, used for the determination of the binding free energies of $\mathrm{X}_{4}-1^{2+}$ towards halides are complementary. CV experiments require the presence of ionic species in form of a supporting electrolyte involving multiple competing electrostatic interactions in solution. UV-vis and NMR titrations can be realized in presence or in absence of such electrolyte salts, thus helping to discriminate the impact of XB among the different noncovalent interactions. Furthermore, electrochemistry allows determining elegantly the affinity constants of the reduced XB-donor species, named $K_{\text {red }}$ in the discussed square scheme model (Scheme 5). These values are very difficult to obtain via UV-vis and NMR spectroscopy, requiring quantitative chemical reduction of the XB-donors prior to the titration experiments. Table 3 summarizes affinity constants and binding free energies for the interaction between $\mathbf{I}_{4} \mathbf{- 1}^{2+}$ and the four anions $\mathrm{Cl}^{-}$, $\mathrm{Br}^{-}, \mathrm{I}^{-}$and OTf ${ }^{-}$in DMF. It is noteworthy that the polar solvent DMF was chosen for solubility reasons, thus giving rise to relatively low formal affinity constants due to solvation of the interacting species. Dependency of the affinity constant on the nature of the solvent has been already reported ${ }^{26}$ but its impact is difficult to explain and to predict.

All methods indicate the strongest interaction being between $\mathbf{I}_{4}-\mathbf{1}^{2+}$ and chloride (Table 3 ), in agreement with the DFT calculations in the gas phase. The corresponding binding energy of $\mathrm{Br}_{4}{ }^{-1}{ }^{2+}\left(-8.5 \mathrm{~kJ} \mathrm{~mol}^{-1}\right)$ is considerable weaker, which can be attributed to the weaker polarization of the Br substituents and is not experimentally measurable for $\mathbf{H}_{4}-\mathbf{1}^{2+}$. When comparing the data from the spectroscopic experiments (UV-vis and NMR) with $\left[\mathrm{I}_{4}-\mathbf{1}^{2+}, \mathrm{Cl}^{-}\right]$it can be stated that the competing electrostatic interactions of the supporting electrolyte salt significantly diminish the formal binding constants of up to one order of magnitude. In both systems, with and without $n \mathrm{Bu}_{4} \mathrm{PF}_{6}$, the order of binding strength was observed as follows: $\mathrm{Cl}^{-}>\mathrm{Br}^{-} \geq \mathrm{I}^{-} \gg \mathrm{TfO}^{-}$. These experimental results together with the obtained XRD structures for the complex $\left[\mathrm{I}_{4}-\mathbf{- 1}^{2+}, \mathrm{Cl}^{-}\right]$ constitute further evidence of halogen bonding being the main driving force for the observed assemblies. Addition of triflate in the solution did not perturb the signals whatever the method, confirming the weak Lewis basicity of this anion.

When comparing the three employed analytical techniques the corresponding results obtained by CV and UV-vis certainly reflect the global electronic effects whereas NMR locally probes 


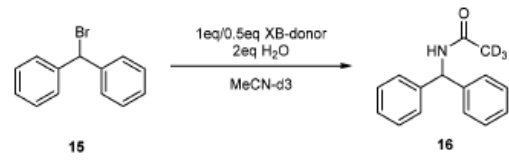

Scheme 7 XB activated solvolysis of benzhydryl bromide to benzhydrylacetamide- $d_{3}$.

distinct sites. However, all methods show the same tendency and confirm the highest affinity constant for the interaction between $\mathrm{I}_{4}-\mathbf{1}^{2+}$ and $\mathrm{Cl}^{-}$. To the best of our knowledge, such a systematic quantification of $\mathrm{XB}$ strength in solution using several analytical techniques has not been reported yet in literature.

\section{Substrate activation/solvolysis}

The determined binding constants are lower than expected for a dicationic chelating XB-donor, but are still high enough to consider potential catalytic activity in organic reactions. The catalytic properties of $\mathrm{I}_{4}-\mathbf{1}^{2+}, \mathrm{Br}_{4} \mathbf{- 1}^{2+}$ and $\mathrm{H}_{4}-\mathbf{1}^{2+}$ were first tested in the Diels-Alder reaction between methylvinylketone and cyclopentadiene. ${ }^{28}$ However, we do not observe any catalytic activity. As the activation of neutral substrates like carbonyl derivatives has proven to be more difficult than the activation of $\mathrm{S}_{\mathrm{N}} 1$-type substrates in halide abstraction reactions, we then turned our attention towards the latter. In this second approach, we investigated the bromide abstraction reaction of benzhydryl bromide in the presence of acetonitrile (Scheme 7)

As mentioned in the introduction, we had previously tested the $4,4^{\prime}$-azobis(halopyridinium) derivatives $\mathrm{I}_{4} \mathbf{2}^{2+}, \mathrm{Br}_{4}-2^{2+}$ and $\mathrm{H}_{4}-2^{2+}$ in this benchmark reaction and we have demonstrated their ability to act as XB-donor catalysts. ${ }^{6}$ However, with these derivatives a side reaction occurred in which the halogen bond donors acted as oxidants towards bromide. One of the main goals of the present study was to prepare iodopyridinium-based bidentate activators which would be stable against halides.

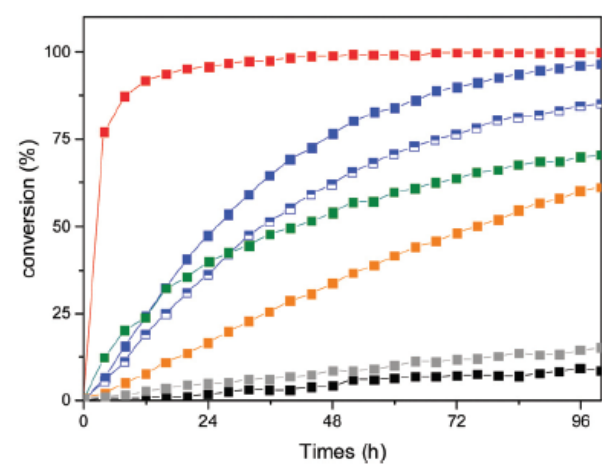

Fig. 10 Solvolysis of benzhydryl bromide with $\mathrm{MeCN}-\mathrm{d}_{3}$ and $\mathrm{H}_{2} \mathrm{O}$ activated by the synthesized $\mathrm{X}_{4}-1^{2+}$ viologenes $\left(\mathrm{I}_{4}-1^{2+}\right.$ in blue, $\mathrm{Br}_{4}-1^{2+}$ in orange, $\mathrm{H}_{4}-\mathrm{1}^{2+}$ in grey and with 0.5 eq. of $\mathrm{I}_{4}-1^{2+}$ in blue/white) over $100 \mathrm{~h}$ at $22.5^{\circ} \mathrm{C}$. For comparison 13 is in red, 14 in green and the background in black.
The catalytic reaction was monitored via ${ }^{1} \mathrm{H}$ NMR in MeCNd3. A stoichiometric amount of $\mathbf{I}_{4}-\mathbf{1}^{2+}$ reaches $97 \%$ conversion, while half of this amount leads to $86 \%$ (Fig. 10). In parallel, using $\mathrm{Br}_{4}-\mathbf{1}^{2+}$ as XB-donor catalyst transforms $64 \%$ of the benzhydryl bromide and $\mathrm{H}_{4}-\mathbf{1}^{2+}$ only $16 \%$. The measured background over the same timespan conduces to $6 \%$ of transformation. The catalyst efficiency of $\mathbf{I}_{4}-\mathbf{1}^{2+}$ and $\mathrm{Br}_{4}-\mathbf{1}^{2+}$ is significantly higher than for the previously reported bis-imidazolium $4 .^{29}$ The iodolium derivative $13,{ }^{30}$ still displays the highest catalytic activity which is certainly due to the higher oxidation state of the iodine(III) center.

This result is in agreement with its high affinity constant to bromide in acetonitrile $\left(K_{\mathrm{a} 30^{\circ} \mathrm{C}}=2.21 \times 10^{6} \mathrm{M}^{-1}\right.$ $\left.\left(-8.8 \mathrm{kcal} \mathrm{mol}{ }^{-1}\right)\right) \cdot{ }^{30,31}$

\section{Conclusions}

Bidentate halogen bond donors with halopyridinium moieties linked by an ethylene bridge were synthesized and structurally characterized by X-ray diffraction analysis and accompanying DFT calculations. Electrochemical measurements indicated clean twofold reductions to the corresponding neutral species, which should be much weaker XB-donors. Binding constants of the dicationic XB-donors to halides were obtained by three techniques: NMR, UV/vis and CV, with the latter also being able to estimate the binding strength of the reduced species - a clear advantage of this electrochemical approach. The data indicate that the presence of electrolyte salts in CV measurements leads to competition with the halides and a decrease of the observed binding constant by about an order of magnitude. Despite the strengths and weaknesses of the different methods, all three techniques revealed the same tendency of relative binding strength to halides, with chloride being the strongest. Compared to CV and UV-vis, NMR spectroscopy seems to significantly underestimate binding strength by almost one order of magnitude even when performed in the same experimental conditions (ionic strength, solvent, concentration...). We suggest that the results obtained with $\mathrm{CV}$ and UV-vis represent the effects on the global electronic structure of molecules, in contrast to NMR spectroscopy, which mainly probes local interactions. The Lewis acidity of the novel bidentate XBdonors was applied in a proof-of-principle case for halide abstraction, in which the chelating donors performed similarly compared to previously established bis(haloimidazolium) compounds. Furthermore, these new catalysts are chemically stable and did not decompose as their azo-bridged analogues. ${ }^{6}$ In contrast to our previously employed activators and catalysts, the new tetrahalo bipyridinium stilbenes are redox active, so that in principle it should be possible to control their catalytic activity by reversible switching the redox state. Future work on this interesting concept is in progress.

\section{Conflicts of interest}

There are no conflicts to declare. 


\section{Acknowledgements}

The work was supported by the Laboratoire d'Electrochimie Moléculaire (UMR 7591 CNRS - Université de Paris) and was also funded by the Deutsche Forschungsgemeinschaft (DFG, German Research Foundation) under Germany's Excellence Strategy - EXC 2033 - 390677874 - RESOLV. Special thanks are going to Dr Sihem Groni for experimental assistance. CF thanks the DAAD for a visiting scholarship (91708797) and a Procop grant (44694PE).

\section{Notes and references}

1 S. Groni, T. Maby-Raud, C. Fave, M. Branca and B. Schöllhorn, Chem. Commun., 2014, 50, 14616.

2 (a) R. Oliveira, S. Groni, C. Fave, M. Branca, F. Mavre, D. Lorcy, M. Fourmigué and B. Schöllhorn, Phys. Chem. Chem. Phys., 2016, 18, 15867; (b) R. Oliveira, S. Groni, A. Vacher, F. Barrière, D. Lorcy, M. Fourmigué, E. Maisonhaute, B. Schöllhorn and C. Fave, ChemistrySelect, 2018, 3, 8874.

3 (a) J. Y. C. Lim, M. J. Cunningham, J. J. Davis and P. D. Beer, Chem. Commun., 2015, 51, 14640; (b) J. Y. C. Lim and P. D. Beer, Eur. J. Inorg. Chem., 2017, 220.

4 G. Creste, S. Groni, C. Fave, M. Branca and B. Schöllhorn, Faraday Discuss., 2017, 203, 301.

5 C. Fave and B. Schöllhorn, Curr. Opin. Electrochem., 2019, $15,89$.

6 F. Kniep, S. M. Walter, E. Herdtweck and S. M. Huber, Chem. - Eur. J., 2012, 18, 1306.

7 A. M. Allgeier and C. A. Mirkin, Angew. Chem., Int. Ed., 1998, 37,894 .

8 J. Choudhury, Tetrahedron Lett., 2018, 59, 487.

9 (a) T. M. Beale, M. G. Chudzinski, M. G. Sarwar and M. S. Taylor, Chem. Soc. Rev., 2013, 42, 1667; (b) C. Laurence, J. Graton, M. Berthelot and M. J. El Ghomari, Chem. - Eur. J., 2011, 17, 10431; (c) A. Caballero, F. Zapata, N. G. White, P. J. Costa, V. Félix and P. D. Beer, Angew. Chem., Int. Ed., 2012, 51, 1876.

10 (a) E. Gleich and Z. Warnket, Phosphorus, Sulfur Silicon Relat. Elem. 1991, 55, 9; (b) K. A. Chudov, K. S. Levchenko, N. O. Poroshin, A. V. Shchegolkov, P. S. Shmelin and E. P. Grebennikov, Russ. Chem. Bull., Int. Ed., 2019, 68, 1565.

11 The chlorinated analogs were synthetized for the sake of completeness, but due to the low halogen bonding capabilities of the bromo derivatives never investigated any further.
12 A. Krasovskiy, V. Krasovskaya and P. Knochel, Angew. Chem., Int. Ed., 2006, 45, 2958.

13 J. Gorecka, C. Heiss, R. Scopelliti and M. Schlosser, Org. Lett., 2004, 6, 4591.

14 J. J. Baldwin, K. Mensler and G. S. Ponticello, J. Org. Chem., 1978, 43, 4878.

15 I. Sasaki, J. C. Daran and G. G. A. Balavoine, Synthesis, 1999, 815.

16 S. Arnaboldi, A. Gennaro, A. A. Isse and P. R. Mussini, Electrochim. Acta, 2015, 158, 427.

17 (a) A. Bondi, J. Phys. Chem., 1964, 68, 441; (b) S. C. Nyburg and C. H. Faerman, Acta Crystallogr., Sect. B: Struct. Sci., 1985, 41, 274

18 C. Y. Legault, CYLview, 1.0b, Université de Sherbrooke, 2009, http://www.cylview.org.

19 E. Engelage, N. Schulz, F. Heinen, S. M. Huber, D. G. Truhlar and C. J. Cramer, Chem. - Eur. J., 2018, 24, 15983.

20 J. Deng, X. Fu, G. Wang, L. Wu and J. Hiang, Electrochim. Acta, 2012, 85, 195.

21 P. Thordarson, Chem. Soc. Rev., 2011, 40, 1305.

22 http://app.supramolecular.org/BindFit/.

23 F. Heinen, E. Engelage, A. Dreger, R. Weiss and S. M. Huber, Angew. Chem., Int. Ed., 2018, 57, 3830.

24 F. Kniep, L. Rout, S. M. Walter, H. K. V. Bensch, S. H. Jungbauer, E. Herdtweck and S. M. Huber, Chem. Commun., 2012, 48, 9299.

25 (a) P. Metrangolo, F. Meyer, T. Pilati, G. Resnati and G. Terraneo, Angew. Chem., Int. Ed., 2008, 47, 6114; (b) A. C. Legon, Phys. Chem. Chem. Phys., 2010, 12, 7736; (c) A. Priimagi, G. Cavallo, P. Metrangolo and G. Resnati, Acc. Chem. Res., 2013, 46, 2686.

26 S. M. Walter, F. Kniep, L. Rout, F. P. Schmidtchen, E. Herdtwevk and S. M. Huber, J. Am. Chem. Soc., 2012 , 134, 8507.

27 D. Brynn Hibbert and P. Thordarson, Chem. Commun., 2016, $52,12792$.

28 S. H. Jungbauer, S. M. Walter, S. Schindler, L. Rout, F. Kniep and S. M. Huber, Chem. Commun., 2014, 50, 6281.

29 S. M. Walter, F. Kniep, E. Herdtweck and S. M. Huber, Angew. Chem., Int. Ed., 2011, 50, 7187.

30 F. Heinen, E. Engelage, A. Dreger, R. Weiss and S. M. Huber, Angew. Chem., Int. Ed., 2018, 57, 3830.

31 E. Engelage, N. Schulz, F. Heinen, S. M. Huber, D. G. Truhlar and C. J. Cramer, Chem. - Eur. J., 2018, 24, 15983. 